\title{
Anomalous pattern of geochemical data recorded in the seismically active site of Pieschi (Southern Italy)
}

\author{
Gerardo Colangelo $\left({ }^{1}\right)$, Giovanni Martinelli $\left({ }^{2}\right)$, Marco Mucciarelli $\left({ }^{3}\right)$, \\ Vincenzo Lapenna $\left({ }^{4}\right)$ and Luciano Telesca $\left({ }^{4}\right)$ \\ (1) Ufficio Difesa del Suolo, Regione Basilicata, Potenza, Italy \\ (2) Agenzia Regionale Prevenzione e Ambiente (ARPA) dell'Emilia Romagna, Sezione di Reggio Emilia, Italy \\ $\left(^{3}\right)$ Dipartimento di Strutture, Geotecnica, Geologia Applicata all'Ingegneria (DiSGG), \\ Università degli Studi della Basilicata, Potenza, Italy \\ ${ }^{(4)}$ Istituto di Metodologie per l'Analisi Ambientale (IMAA), CNR, Tito Scalo (PZ), Italy
}

\begin{abstract}
This work explores three years of geochemical signals recorded by Pieschi station (Southern Italy). The measuring station is located in a thermal spring located in the Southern Apennines Chain, one of the most seismically active areas of the Mediterranean region. The spring is located close to a geophysical monitoring network installed in 2001 by IMAA-CNR. The probe is able to record temperature and water conductivity with a sampling rate of $10 \mathrm{~min}$. From November 2001 to February 2005 several anomalous variations of water conductivity were recorded. Correlation analysis with selected local earthquakes was carried out to identify events inducing strain effects in the investigated area.
\end{abstract}

Key words earthquakes - geochemical signals time series

\section{Introduction}

Deep seated fluids have been widely investigated to monitor possible crustal strains possibly linked to earthquakes (e.g., Wakita et al., 1988). Basilicata Region (Southern Italy) experimented several strong seismic events in the past (Gruppo di Lavoro CPTI, 1999). The abundance of thermal spring sources and gas emissions in Basilicata evidence intense local faulting and enhanced characteristics of crustal per-

Mailing address: Dr. Gerardo Colangelo, Ufficio Difesa del Suolo, Regione Basilicata, C.so Garibaldi 139, 85100 Potenza, Italy; e-mail: gerardo.colangelo@regione.basilicata.it meability induced by tectonic activity. Most suitable local deep seated fluids useful for geodynamic monitoring were described by Balderer and Martinelli (1995) and by Martinelli and Albarello (1997). Among them Pieschi thermal spring is characterized by absence of anthropic noise and by clues of possible sensitivity to seismic events in the past (Martinelli, 2004).

Pieschi spring source (fig. 1) is located in the municipality of Tito (Basilicata region) and is characterized by a flow rate of about $5 \mathrm{l} / \mathrm{s}$ and $T^{\circ}=20^{\circ}$. Acquifer is fed by the local Mount Pieschi carbonatic rock which belong to the Campanian platform. Intense local faulting allows water infiltration up to $1 \mathrm{~km}$ depth while a hydraulic head is responsible for water outflow. Sodium carbonate geochemical character and the about absence of Tritium ( $<1.3$ T.U.) are consistent with a long path feeding circuit and with long residence time of water into the reservoir estimable in $>40$ years. The constancy of 


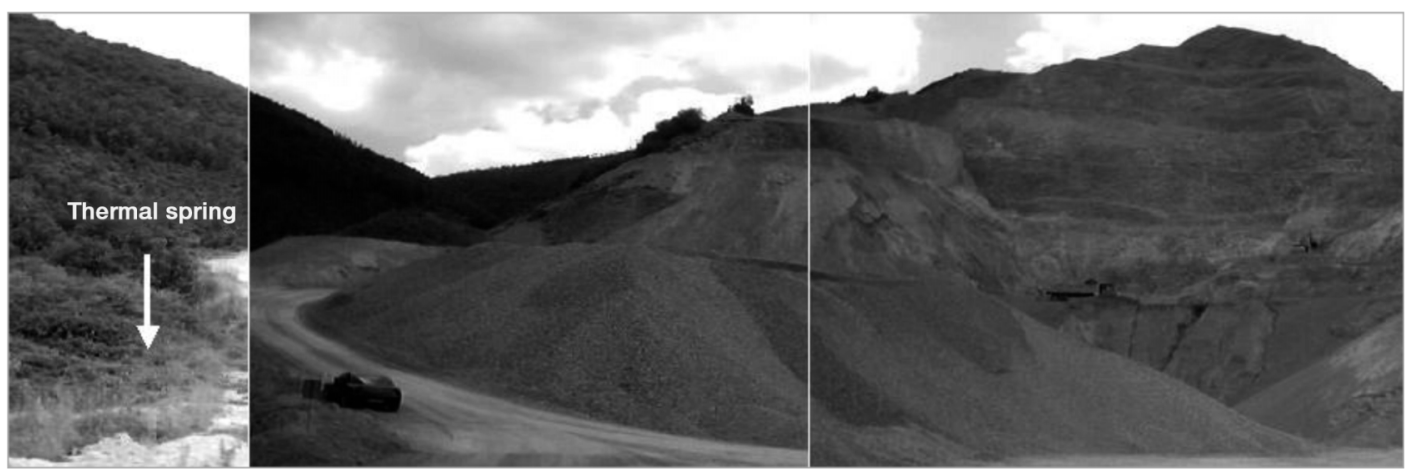

Fig. 1. Thermal spring where Pieschi station has been installed.

flow rate allowed the exploitation of thermal waters in a local resort, due also to relatively high $\mathrm{H}_{2} \mathrm{~S}$ concentration. Long residence time and constancy in flow rate inhibit the short term effects of rain in water parameters. The meanwhile some chemico-physical characteristics of Pieschi spring changed during the 1857 , $M_{e}=6.9$ earthquake (Martinelli, 2004), thus the possible sensitivity of local fluid to crustal deformative processes and relatively high signal/ noise characteristics induced us to monitor Pieschi spring.

\section{Seismological setting}

The Southern Apennines are a fold-and-thrust belt built on from late Oligocene to Pleistocene. The chain is mainly composed of MesozoicCenozoic sedimentary cover from the Ligurian oceanic crust and the western passive margin of the Adriatic Plate, and of the Neogene-Pleistocene piggyback basin and foredeep deposits of the active margin. Recent shortening occurred at the belt front deforming Pleistocene sediments and volcanics whereas widely documented extension is still active along the Apennines axis. Major extensional features are located along the Tyrrhenian side of the chain. The belt is also affected by Plio-Quaternary strike-slip faults (Schiattarella, 1998, and references therein).

From the Tyrrhenian Sea to the Adriatic (Apulian) Foreland, and from the top to the bot- tom of the wedge, the following tectonic units are observed (Pescatore et al., 1999, and references therein): 1) Jurassic to Oligocene polydeformed ophiolitic units, unconformably covered by syntectonic deposits, Early Miocene in age (Ligurian units); 2) a carbonate platform unit (Campania-Lucania platform), whose age ranges from Late Triassic to Early Miocene; 3) several units mainly composed by deep-sea sediments, ranging from Early Triassic to LowerMiddle Miocene; 4) a frontal imbricate fan made up of Cretaceous to Lower Miocene deepsea marls, shales and sandstones, covered by Middle to Upper Miocene syntectonic deposits; 5) Pliocene to Pleistocene foredeep clastic deposits; 6) the Apulian carbonate platform, which has been partly incorporated at the base of the orogenic wedge, forming toward east the less deformed foreland area.

The most ancient rocks of the Lagonegro pre-orogenic successions are present in the investigated area. They are composed of shallowwater siliciclastic sediments, organogenic limestones and, towards the top, of deep-sea deposits (Monte Facito Fm, Lower-Middle Triassic). The overlying pelagic succession is characterised by Upper Triassic to Jurassic carbonate and siliceous sediments (Calcari con Selce and Scisti Silicei Fms). During Early Cretaceous times, turbiditic sedimentation took place (Galestri Fm), followed by Late CretaceousOligocene calcareous-clastic and clayey sedimentation (Pescatore et al., 1999). 
From the seismological point of view, the Campano-Lucano sector of the Southern Apennines Chain is one of the most active areas of the Mediterranean region. In particular in February 1826 an earthquake, reaching up to VIII degree on the MCS scale (Alessio et al., 1995), hit the village of Tito where the geochemical station of geophysical monitoring network is located (Colangelo et al., 2004) installed by IMAA-CNR (fig. 2). One of the most historically important events, the December 16, 1857 ( $I=$ XI MCS) normal-faulting earthquake (Mallet, 1862), occurred close to Marsico Nuovo village in Val d'Agri. On November 23, 1980 $\left(M_{s}=6.9\right)$, a large normal-faulting earthquake occurred in the nearby Irpinia area. Seismic activity occurred after the 1980 event consisting of medium intensity events $(M<5.5)$ located close to the border between Campania and Basilicata regions (Alessio et al., 1995). The May 5, $1990\left(M_{D}=5.0\right.$, ING-National Institute of Geophysics) and the May 26, $1991\left(M_{D}=\right.$
=4.7) earthquakes took place to the north of Potenza town (Tertulliani et al., 1992). These events were generated by a strike-slip fault system with WE direction, perpendicularly oriented toward the Apennines Chain (Ekström, 1994), located in such a way as to limit toward north and south two great seismogenetic faults that caused the 1857 Val d'Agri and 1980 Irpinia earthquakes respectively.

On April 18, 2002 a seismic sequence occurred along the northern side of the PergolaMelandro Basin. The $M_{w}=4.4$ main shock occurred at a depth of $9 \mathrm{~km}$, and was followed by a small number of $1.4 \leq M_{d} \leq 3.4$ aftershocks. The distribution of the earthquakes belonging to this sequence is concentrated within $3 \mathrm{~km}$ distance from the main shock. The mean depths of the shocks range between 4 and $15 \mathrm{~km}$, and the CMT solution for the main shock suggests a prevailing normal faulting mechanism with NE-SW direction of extension (see Cucci et al., 2004 for further details).

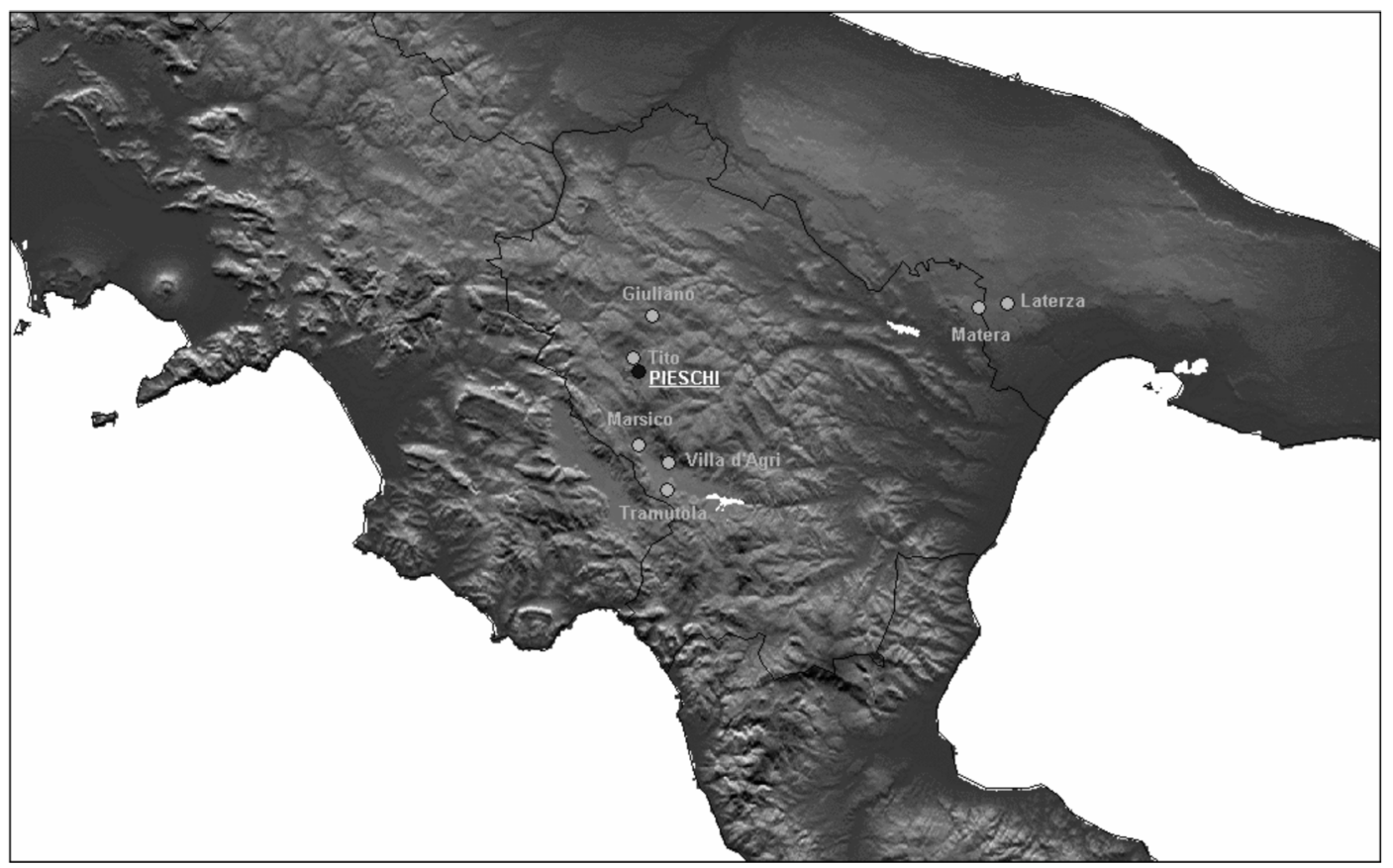

Fig. 2. Location of Pieschi geochemical station. 


\section{The monitoring station}

The monitoring station is constituted by Greenspan EC-250 equipment able to continuously monitor and record temperature and electric conductivity of waters. In particular the magnetic based toroidal sensor of monitoring equipment allows the collection of reliable data over time since it is not affected by possible scales effect due to plastic material protection. The monitoring station is equipped with a car battery able to supply electric energy for several months. A slight seasonal effect in temperature is to be accounted for since water parameters are collected at a depth of about $30 \mathrm{~cm}$. The pool of the spring source is protected by local natural morphologic features able to inhibit possible rain effects. Presented here are data collected in the period November 2001-January 2005. Short data missing periods are due to maintenance activities during battery changeover. The sampling rate was adjusted to one datum every ten minutes.

\section{Results and discussion}

During the past three years some anomalies in geochemical signals recorded at Pieschi site have been recorded. The anomalous signals were correlated with the seismic activity (fig. 3) extracted using the Dobrolovsky method (Dobrolovsky, 1992). The anomalous patterns observed in the time series are the following:

1) Time interval 1 , from November 2001 to September 2002. At the beginning the temporal
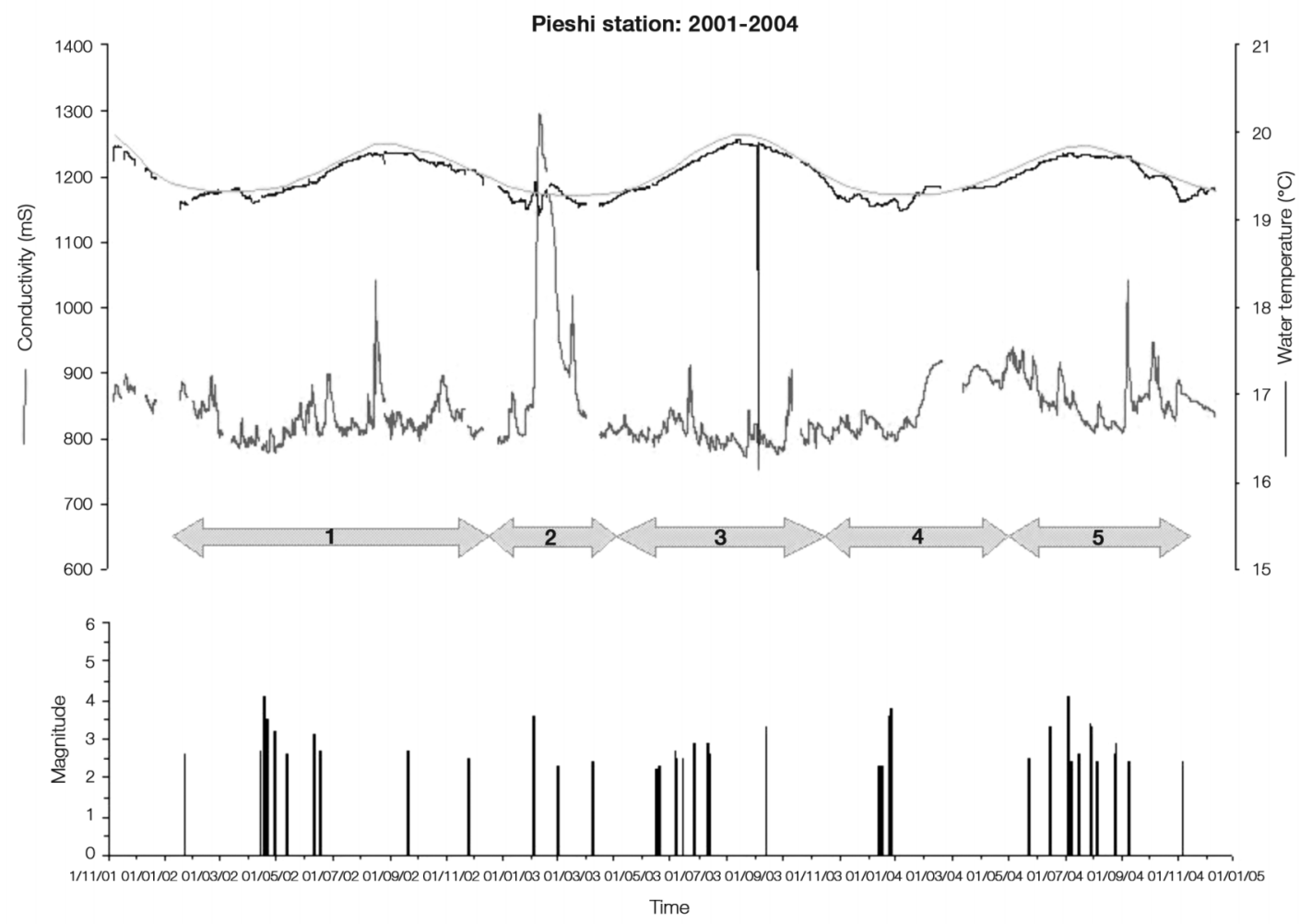

Fig. 3. Water temperature and water conductivity recorded at Pieschi station (top) and local seismicity occurred in the investigated area (bottom) during the observation period. 

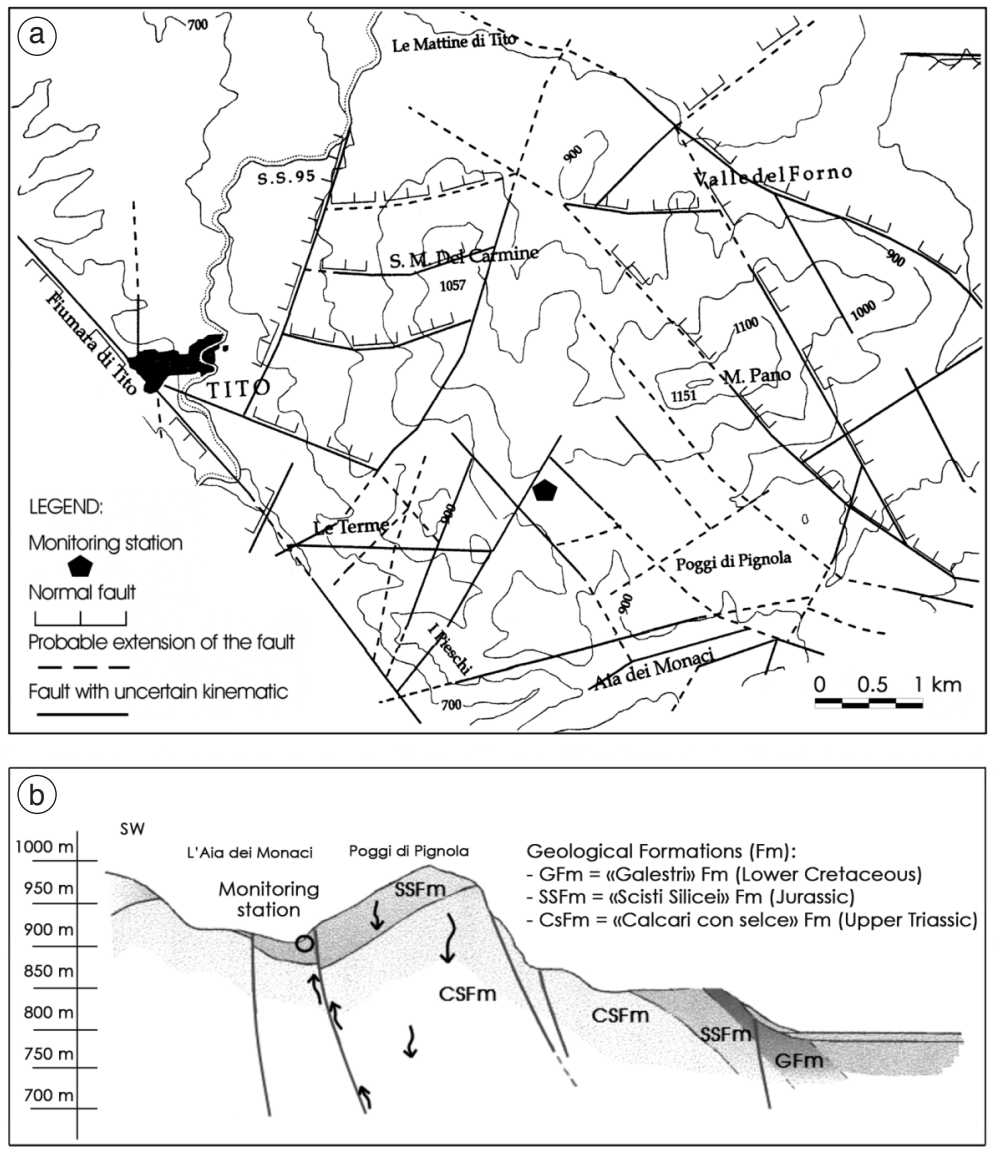

Fig. 4a,b. a) Tectonic map of the investigated area; and b) geological section of the geothermal area of Pieschi (Coviello, 1999, modified).

and epicentral distribution of the sismicity occurred during this period was characterized by a clusterization (fig. 3). The epicentres, indicated in fig. $4 \mathrm{a}, \mathrm{b}$ by the symbol $\downarrow$ are quite far from the station; therefore the strongest variation in geochemical signals could be associated with the earthquake (indicated by the arrow) that occurred after the seismic cluster, whose epicentre is not included in the area of the previous seismic cluster, and whose depth is about $4.1 \mathrm{~km}$ (from IN$\mathrm{GV})$, the most superficial event. During this period significant variations were observed in selfpotential data recorded by the Tito IMAA monitoring network (Telesca and Lapenna, 2004).
2) Time interval 2, from October 2002 to May 2003. During this time interval the water conductivity was characterized by the strongest variation that occurred throughout the observation period (fig. 3 ). The sharp increase is of about $350 \mu \mathrm{S} / \mathrm{cm}$ (resolution $0.1 \mu \mathrm{S} / \mathrm{cm}$ ) and at the same time a strong variation in the thermal water temperature was recorded at about $0.30^{\circ} \mathrm{C}$ (resolution $0.01^{\circ} \mathrm{C}$ ). The cyan line, superimposed on the water temperature, represents the typical annual excursion. Corresponding to the seismic events the deviation of the temperature from the cyclic component is very clear. The epicentres of the earthquakes (as indicated in fig. 4a,b by the 


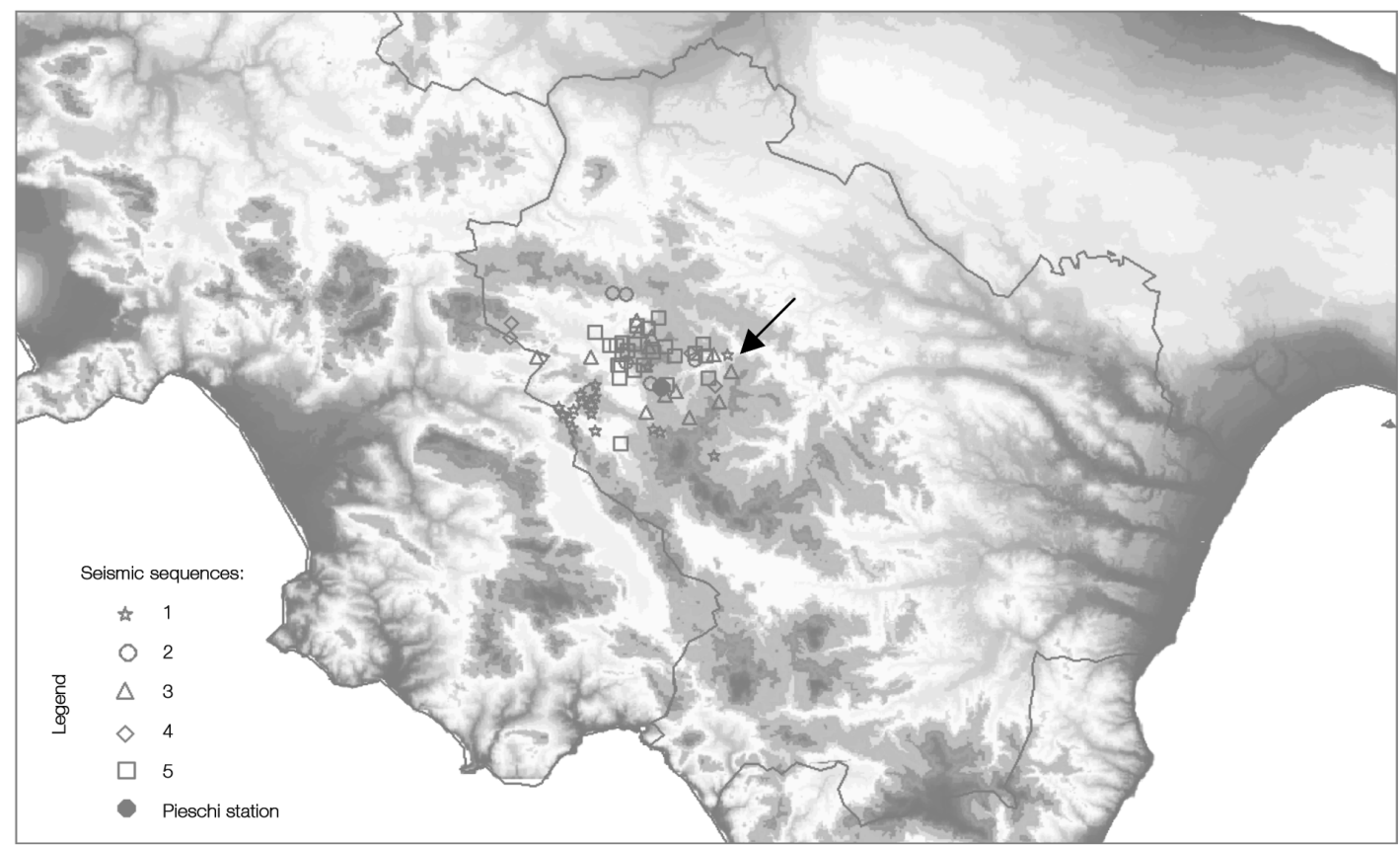

Fig. 5. Epicentral distribution of the earthquakes occurring in the investigated area: the symbol $\downarrow$ labels the events occurring from November 2001 to September 2002; the symbol $\bigcirc$ labels the events occurring from October 2002 to May 2003; the symbol $\Delta$ labels the earthquakes occurring from June 2003 to December 2003; the symbol $\diamond$ indicates the earthquakes occurring from January 2004 to June 2004; and the symbol $\square$ indicates the events occurring from July 2004 to January 2005.

symbol $\bigcirc$ ) that occurred during this time interval are very close to the geochemical station. This suggests a very close connection between the anomalous value in the water conductivity and the faults system of investigated area (fig. $4 a, b)$.

3) Time interval 3, from June 2003 to December 2003. During this time interval, the water conductivity was characterized by some sharp variations, as that indicated in fig. 3 by the arrow, but not strong as in the previous time intervals. Close to the monitoring station a cluster of seismic events, indicated in fig. 5 by the symbol $\Delta$, occurred. Therefore a close link could be supposed between the occurrence of this seismic cluster and the sharp variation of the signal.

4) Time interval 4, form January 2004 to June 2004. During this period no anomalous values in the signal were recorded (fig. 3) and the low seismic activity occurred far from the station (fig. 5 symbol $\diamond$ ).

5) Time interval 5, from July 2004 to January 2005. A few sharp increases in the signal could be observed (fig. 3), very probably linked with seismic events, indicated in fig. 5 by the symbol $\square$.

\section{Conclusions}

Significant anomalous patterns in hydrogeochemical signals recorded in thermal water of Pieschi station have been related to the occurrence of seismic events, whose epicentres are located close to the station. These fluctuations can be attributed to crustal deformation processes though not all local seismic events were preceded or followed by the detection of anomalous pattern. The results presented in this 
paper are still preliminary and similar investigations performed over other geochemical data sets, measured in seismic areas have to be performed to contribute to the earthquake prediction problem.

\section{REFERENCES}

Alessio, G., F. Esposito, A. Gorini and S. Porfido (1995): Detailed study of the Potentino seismic zone in the Southern Apennines, Tectonophysics, 250, 113-134.

BALDERER, W. and G. MartinELli (1995): Geochemistry of groundwaters and gases occurring in the 23 November 1980 earthquake area, Environ. Geochem. Health, 16, 147-164.

Colangelo, G., M. Balasco, V. Lapenna and L. Telesca (2004): Design and installation of a monitoring network to investigate the correlations between geoelectrical fluctuations and seismicity of Basilicata region (Southern Italy), Phys. Chem. Earth, 29, 313-320.

Coviello, M. (1999): Geologia ed evoluzione neotettonica del Bacino del «Piano di S. Loja» (Tito Scalo, Appennino Lucano), MS Thesis (Università degli Studi della Basilicata), pp. 63.

Cucci, L., S. Pondrelli, A. Frepoli, M.T. Mariucci and M. Moro (2004): Local pattern of stress field and seismogenic sources in the Pergola-Melandro Basin and the Agri Valley (Southern Italy), Geophys. J. Inter., 156 (3), $575-583$.

DOBROVOLSKY, I.P. (1992): Analysis of the preparation of a strong tectonic earthquake, Phys. Solid Earth, 28 (6), 481-493.

EкSTRÖM, G. (1994): Teleseismic analysis of the 1990 and 1991 earthquakes near Potenza, Ann. Geofis., XXXVII (6), 1591-1599.

GrupPo di LAVORO CPTI (1999): Catalogo Parametrico dei
Terremoti Italiani (ING, GNDT, SGA, SSN, Bologna), pp. 92.

MALLET, R. (1862): The first principle of observational seismology as developed in the report to the Royal Society of London of the expedition made by command of the Society into the interior of the Kingdom of Naples to investigate the circumstances of the great earthquake of December 1857, London (reprint by Istituto Nazionale di Geofisica, Roma, 1987).

MartinelLi, G. (2004): Fluidi sotterranei naturali e terremoti: le osservazioni di Robert Mallet nel contesto idrologico delle province di Salerno e Potenza, in Viaggio nelle Aree del Terremoto del 16 Dicembre 1857, edited by G. FERrARI (SGA, Bologna), 209-220.

Martinelli, G. and D. Albarello (1997): Main constraints for siting monitoring networks devoted to the study of earthquake related hydrogeochemical phenomena in Italy, Ann. Geofis., XL (6), 1505-1522.

Pescatore, T., P. Renda, M. Schiattarella and M. TraMUTOLI (1999): Stratigraphic and structural relationship between Meso-Cenozoic Lagonegro Basin and coeval carbonate platforms in Southern Apennines, Italy, Tectonophysics, 315, 269-286.

Schiattarella, M. (1998): Quaternary tectonics of the Pollino Ridge, Calabria-Lucania boundary, Southern Italy, in Continental Transpressional and Transtensional Tectonics, edited by R.E. Holdsworth, R.A. STRACHAN and J.F. Dewey, Geol. Soc. Spec. Publ. 135, 341-354.

Telesca, L. and V. Lapenna (2004): Magnitude and sign scaling in power-law correlated geoelectrical time series measured in Southern Italy, Nat. Hazards Earth Syst. Sci., 4, 669-677.

Tertulliani, A., M. AnZidei, A. Maramai, M. Murru and F. Riguzzi (1992): Macroseismic study of the Potenza (Southern Italy) earthquake of 5 May 1990, Nat. Hazards, 6, 25-38.

WAKITA, H., Y. NAKAMURA and Y. SANO (1988): Short-term and intermediate-term geochemical precursors, Pure Appl. Geophys., 126, 267-278. 